\title{
Corrected Transposition of the Great Arteries with Several Associated Anomalies in a 68-Year-Old Patient
}

\author{
José Luiz Balthazar Jacob
}

São José do Rio Preto, SP - Brazil

\begin{abstract}
Few patients with corrected transposition of the great arteries survive past 50 years of age because of the association with congenital defects, development of total atrioventricular block, and right ventricular dysfunction. We report the case of a male patient with dextrocardia in situs solitus and corrected transposition of the great arteries associated with a wide atrial septal defect and severe pulmonary valvar and subvalvar stenoses. The patient also developed a large aneurysm on the pulmonary artery, total atrioventricular block diagnosed 8 years earlier, symptoms of dysfunction of the systemic ventricle in the previous 2 years, insufficiency of the left atrioventricular valve, and aortic regurgitation. Despite all these associated anomalies, the patient developed class III cardiac decompensation only at the age of 68 years, which makes this case a rarity. The patient was clinically treated, and was discharged from the hospital in good condition.
\end{abstract}

Corrected transposition of the great arteries is a rare congenital heart disease in which atrioventricular and ventriculoarterial discordance exist concomitantly ${ }^{1}$. Prevalence of this anomaly is approximately $0.5 \%$ to $1.4 \%$ of all the congenital heart diseases ${ }^{2-4}$. Few patients survive past 50 years of age due to the presence of associated congenital defects, development of total atrioventricular block, and right ventricular dysfunction, which limit survival ${ }^{1,5}$. We report the case of a male patient with corrected transposition of the great arteries with dextrocardia in situs solitus, atrial septal defect of the ostium secundum type, severe pulmonary stenosis with development of an aneurysm in the pulmonary artery, total atrioventricular block, and significant dysfunction of the systemic ventricle with moderate regurgitation of the left atrioventricular valve and aortic insuffici-

Instituto de Moléstias Cardiovasculares de São José do Rio Preto Mailing address: José Luiz Balthazar Jacob - IMC - Rua Castelo D’Água, 3030 15015-210 - São José do Rio Preto, SP, Brazil - E-mail: ljacob@cardiol.br English version by Stela Maris C. e Gandour ency (++/4). Despite all these associated anomalies, the patient was in functional class III at the age of 68 years, which makes this case a rarity. The patient was treated with digitalis, diuretics, and vasodilator, and was discharged in good conditions.

\section{Case Report}

A 68-year-old white male patient complained of progressive dyspnea over the previous 2 years, which evolved into dyspnea on mild exertion currently. In 1992, the patient underwent implantation of an endocavitary pacemaker at the Instituto do Coração of Dourados, in the state of Mato Grosso do Sul, Brazil. The patient denied syncopal episodes prior to pacemaker implantation. On physical examination, the patient was acyanotic and dyspneic; his blood pressure was $110 / 60 \mathrm{mmHg}$, and his heart rate was $76 \mathrm{bpm}$. On cardiac auscultation, the second cardiac sound was loud in the lower left sternal margin, and in the aortic and pulmonary areas, with the first component much more intense than the second. The $3^{\text {rd }}$ cardiac sound and a mesodiastolic murmur were audible in the lower right sternal margin; however, no gallop rhythm existed. An intense early systolic click was audible in the lower left sternal margin and in the pulmonary area. A rough holosystolic murmur could be heard in the pulmonary area, and another high-frequency holosystolic murmur with musical timbre could be heard in the lower right sternal margin. A rasping diastolic murmur was audible in the pulmonary and accessory aortic areas. The liver was palpable $2 \mathrm{~cm}$ from the right costal margin and mild edema of the lower limbs was present. The electrocardiogram showed endocavitary pacemaker rhythm (fig. 1A). The chest X-ray showed dextrocardia in situs solitus and significant cardiomegaly; the cardiac silhouette had a round shape. The source of the endocavitary pacemaker could be seen in the right subclavicular region, and the electrode was located in the cardiac apex, to the right. The pulmonary vascular net was normal and the mediastinum widened, with the image of the descending aorta running to the left of the dorsal spine (fig. 1B). Doppler color echocardiography showed the cardiac apex to the right, with ventricular inversion. The 


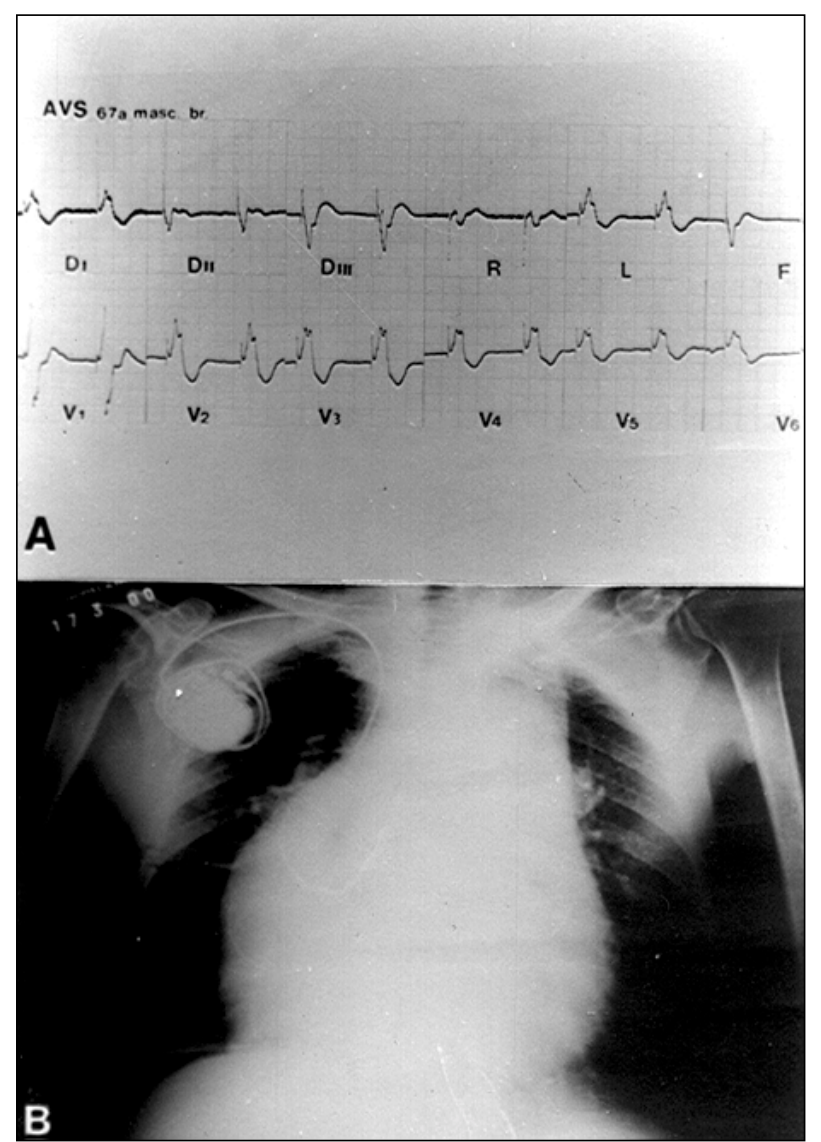

Fig. 1 - A) Electrocardiogram showing the rhythm of endocavitary pacemaker; B) Chest X-ray in AP view, showing cardiomegaly, round shape of the cardiac silhouette, and cardiac apex to the right. Note enlargement of the mediastinum and presence of the pacemaker source with the endocavitary electrode.

right atrium was connected through the mitral valve to the anatomically left ventricle, located to the right. The left atrium was connected through the tricuspid valve to the morphologically right ventricle, located to the left. Atrial septal defect of the ostium secundum type with a diameter of $20 \mathrm{~mm}$ was present, as were significant pulmonary subvalvar and valvar stenoses, with an aneurysm on the pulmonary trunk (fig. 2A and B) and a gradient of $69 \mathrm{mmHg}$ on Doppler echocardiography. The regurgitation of the left atrioventricular valve was moderate, with a significant contractile deficit in the systemic ventricle. The pulmonary artery emerged from the left ventricle, which was located to the right, and the aorta emerged from the right ventricle, located to the left, with aortic valve regurgitation. Cardiac catheterization was indicated and showed coronary arteries free from obstructions, and confirmed the echocardiographic findings, which established the diagnosis of dextrocardia in situs solitus with corrected transposition of the great arteries. Manometry revealed right ventricular systolic pressure of $94 \mathrm{mmHg}$. Pulmonary artery pressure was not obtained because the manipulation of the catheter caused repetitive impacts on the electrode of the endocavitary pacemaker. Due to the risk of dislocation of the electrode and because we already had obtained the gradient with Doppler echocardiography, we preferred not to insist on the attempt to cathete-
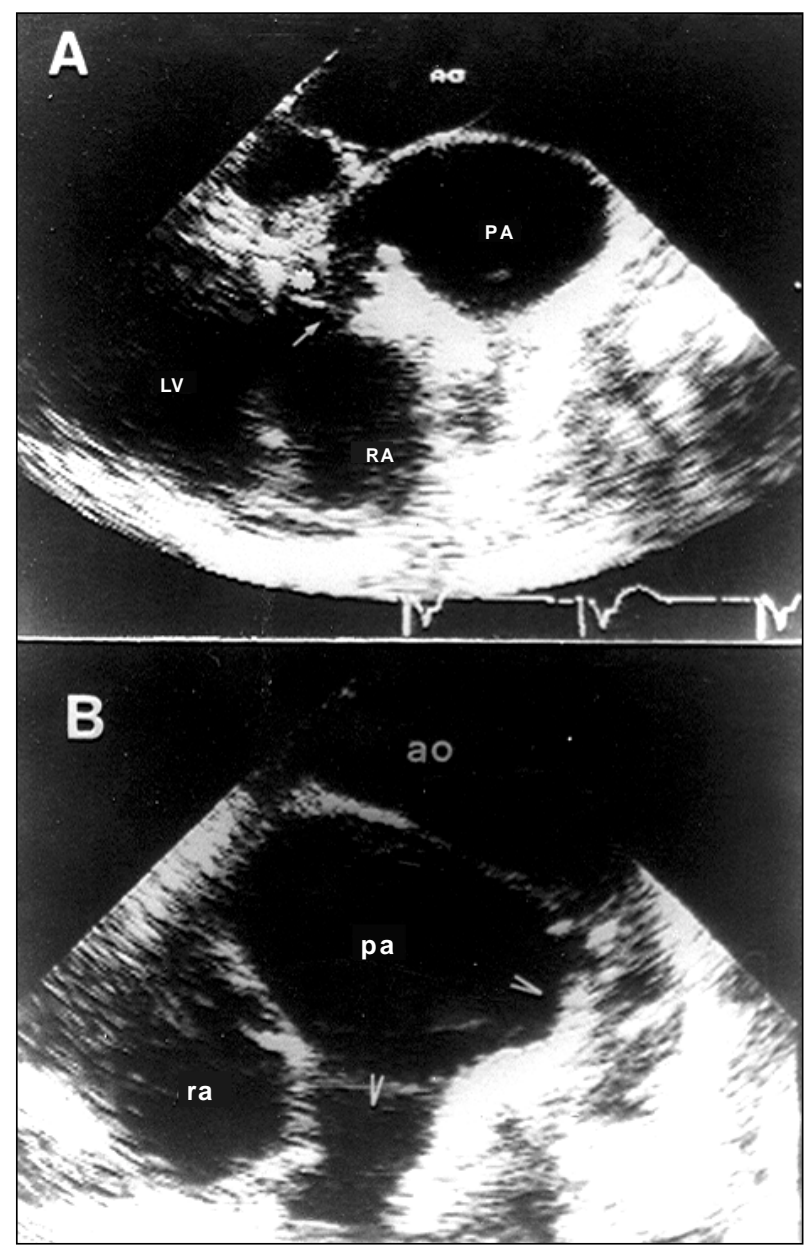

Fig. 2-A) Echocardiogram showing the right atrium (RA) connected to the morphologically left ventricle (LV), from where the pulmonary artery (PA) emerges, and the presence of subpulmonary stenosis (arrow). Note the great dilation of the PA; B) Evidence of aneurysm of the pulmonary artery (PA) $67 \mathrm{~mm}$ in diameter. Note the disproportion between the diameters of the pulmonary artery and right atrium (RA).

rize the pulmonary artery. On cineangiocardiography, we could see moderate regurgitation of the left AV valve, aortic insufficiency (++/4), a wide atrial septal defect of the ostium secundum type, significant pulmonary valvar and subvalvar stenosis, with aneurysm of the pulmonary trunk, and significant diffuse hypocontractility of the right ventricle (fig. 3 A, B, C, D). The patient was treated with digitalis, diuretics, and a vasodilator and had evident clinical improvement, being discharged compensated from the hospital.

\section{Discussion}

Corrected transposition of the great arteries is an uncommon congenital heart disease, and, when it does not have associated defects, it is even rarer, accounting for $1 \%$ of cases ${ }^{2,3}$. In these situations in which no defect is associated, survival is longer. The literature reports the case of an 80 -year-old male patient ${ }^{6}$. However, even in patients with no associated anomalies at birth, later appearance of regurgitation of the left atrioventricular valve, dysfunction of the systemic ventricle, and total atrioventricular block allow few patients to survive past the age of 50 years ${ }^{5}$. The most 


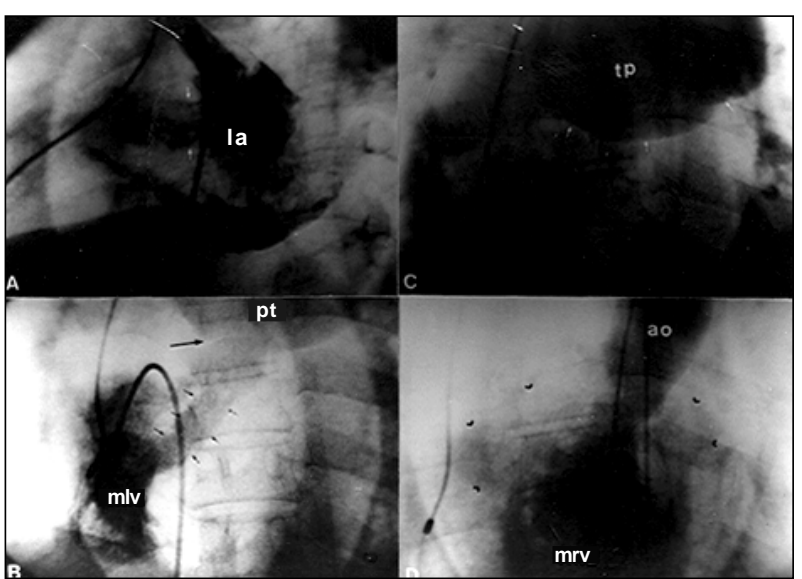

Fig. 3 - A) Angiography in the right superior pulmonary vein showing the normal drainage to the left atrium (LA) and passage of the contrast medium to the right atrium, through a wide atrial septal defect (white arrows); B) angiography in the morphologically left ventricle (MLV), from where the pulmonary trunk emerges (PT), showing pulmonary subvalvar (short arrows) and valvar (arrow) stenoses; C) angiography showing the aneurysm of the pulmonary trunk (PT), which is delimited by short white arrows; D) angiography in the morphologically right ventricle (MRV), note the rough trabeculation. The aorta (Ao) emerges from this cavity, and opacification of the left atrium (arrow heads) resulting from regurgitation of the left atrioventricular valve can be seen

common associated defects are ventricular septal defect, present in approximately $80 \%$ of cases, and pulmonary stenosis, which occurs in 57 to $70 \%$ of cases ${ }^{2,3,7}$. Dextrocardia in situs inversus is very rare; however, dextrocardia in situs solitus is frequent ${ }^{3,4}$. The natural history of this heart defect is not very well defined, and it depends on the associated defects and their repercussions ${ }^{2,3}$, as well as on the capacity of the right ventricle to preserve its function ${ }^{1}$. Hornung et al. ${ }^{1}$ showed that the function of the systemic ventricle deteriorates with age; their patients with normal right ventricular ejection fraction were, on average, 7 years old. These authors confirmed through their experience that, frequently, right ventricular failure occurs from the $3^{\text {rd }}$ decade of life on. Dysfunction of the right ventricle, from which the aorta emerges, is one of the most investigated and debated points in this heart disease. For many years, the cause of the progressive failure of this ventricle was believed to be its ejection against the systemic territory, which resulted in having to support an elevated pressure to which it was not adapted.
Since 1989, Dimas et al. ${ }^{8}$ have postulated that the right ventricle is able to maintain adequate function for a long time when playing the role of the systemic ventricle, even in the presence of associated lesions that impose significant hemodynamic load to the cavity. They suggest that other factors, such as volume overload for a long period of time and intermittent episodes of imbalance between offer and consumption of myocardial oxygen, may be determinant in the systolic dysfunction. Hornung et al. ${ }^{1}$ directed their study specifically to myocardial perfusion and showed an evident correlation between extension of the defects of perfusion and the degree of dysfunction in the systemic ventricle in the corrected transposition of the great arteries. However, our patient is undoubtedly a rarity, because he has associated congenital defects (dextrocardia in situs solitus, atrial septal defect of the ostium secundum type, and pulmonary stenosis) and developed total atrioventricular block over the years, requiring pacemaker implantation. Later, the patient evolved with systolic dysfunction of the systemic ventricle, moderate regurgitation of the left atrioventricular valve, and aortic insufficiency. Despite all these associated anomalies, the patient only manifested significant cardiac decompensation with functional class III at the age of 68 years. The literature shows that surgical treatment of the anomalies associated with corrected transposition of the great arteries has a high mortality and is frequently associated with the development of surgical total atrioventricular block. The surgery performed with the access route through the right atrium has a mortality rate of approximately $18 \%{ }^{2}$ and, when performed through the biventricular access, its mortality rate may reach $60 \%{ }^{3}$. Surgical results are also very poor in patients with impairment of the right ventricle in corrected transposition of the great arteries; therefore, surgery must be performed as early as possible, before significant systolic dysfunction ${ }^{2,7,8}$. Based on this, we chose to treat the patient clinically with digitalis, diuretic, and vasodilator. His congestive heart failure was compensated, and the patient was discharged in good clinical condition.

We believe this to be the oldest patient with corrected transposition of the great arteries with so many complicating factors and anomalies whose case is reported in the literature and whose diagnosis was established in vivo.

\section{References}

1. Hornung TS, Bernard EJ, Celermajer DS, et al. Right Ventricular Dysfunction in Congenitally Corrected Transposition of the Great Arteries. Am J Cardiol 1999; 84: 1116-9.

2. Losekoot TG, Becker AE. Discordant atrioventricular connexion and congenitally corrected transposition. In: Anderson RH, Macartney FJ, Shinebourne EA, Tynan M, eds. Paediatric Cardiology. Edinburgh: Churchill Livingstone, 1987: 867-83.

3. Gurtner HP. "Corrected" transposition of the great arteries. In: Grahan G, Rossi E, eds. Heart Disease in Infants and Chindren. London: Edward Arnold Ltd, 1980: 351-5.

4. Ruttenberg HD. Corrected transposition of the great arteries and splenic syndromes. In: Adams FH, Emmanouilides GC, Riemenschneider TA, eds. Heart Di- sease in Infants, Children and Adolescent. $4^{\text {th }}$ ed. Baltimore: Williams \& Wilkins, 1989: 424-33.

5. IkedaU, Furuze M, Suzuku O, Kimura K, Sekiguchi H, Shimada K. Long-term survival in aged patients with corrected transposition of the great arteries. Chest 1992; 101: 1382-5.

6. Pite AM, Pardo FA, Mayor JLB, Higueras J. Corrected transposition of the great arteries. N Engl J Med 1996, 334: 866-7.

7. Lundstrom U, Bull C, Wyse RKH, Somerville J. The natural and "unnatural" history of congenitally corrected transposition. Am J Cardiol 1990; 65: 1222-9.

8. Dimias AP, Moodie DS, Sterba R, Gill CC. Long-term function of the morphologic right ventricle in adult patients with corrected transposition of the great arteries. Am Heart J 1989; 118: 526-30. 